\title{
FACTORS AFFECTING SAFETY BEHAVIOR AT CONSTRUCTION COMPANIES IN BATAM
}

\author{
Agustinus Setyawan ${ }^{1)}$, Lily Sudhartio ${ }^{2)}$, Bukti Rantau ${ }^{3)}$ \\ ${ }^{1,2,3)}$ Universitas Internasional Batam, Indonesia \\ Corresponding author: agustinus.setyawan@uib.ac.id
}

\begin{abstract}
The relatively high number of work accidents in the construction sector in Indonesia causes a lot of losses both material and non-material to workers, construction entrepreneurs and the country's image. This encourages us to investigate further what factors influence the safety behavior of workers in construction activities. This research was applied with a survey method, namely by distributing questionaires to 105 respondents. The questionnaire questions were compiled through a review of previous journals that analyzed the factors that influence worker safety behavior. The respondents sampled were Occupational Safety and Health Officer (AK3). As regulated in the Work Safety Law No. 1 year 1970 which is mandated as the representative of the government in the workplace. The AK3 as safety officer which is used as a sample is AK3 whom has construction activities in Batam. The technique used by the researcher is purposive sampling, which is a technique to determine the sample by using a special selection method so that the sample can be properly used for processing. After the respondents' results were collected, the authors tested the data using SPSS software with a Confirmatory Factor Analysis (CFA) approach. From the results of the SPSS processing that the author uses, it is found that the weighting classification of the influence of factors that affect work safety behavior in construction activities in Batam. The results of this study lead to the conclusion that the assumptions used as a references are indeed proven to contribute to work safety behavior in construction activities. Leadership and work pressure factors both together as the dominant factors affecting worker safety behavior in construction activities in Batam are followed by the influence of co-workers, training, and company management commitment in sequence as factors contributed. This needs to be a concern in construction activities in Batam. Limited resources in construction activities trigger whether work safety behavior is implemented or neglected. This of course affects the performance of construction activities which leads to a commitment to completion of construction work and the objectives of the company organization in general.
\end{abstract}

Keywords: Management Safety Commitment, Training, Co-Worker Influence, Leadership, Work Pressure, Safety Behavior

\section{Introduction}

Work is a basic human right. The Republic of Indonesia guarantees this in Article 27 paragraph 2 of the 1945 Constitution, which has undergone four amendments, which states that, "Every citizen has the right to work and a decent living for humanity". The irony is that many workers have had accidents at the place where they are doing their work. The Employment Social Security Administration (BPJS) noted that the number of work accidents in Indonesia tends to continue to increase. As many as 123 thousand cases of work accidents were recorded throughout 2017. There was an increase in work accidents of around 20 percent compared to 2016 nationally, said Director of BPJS Employment Services Krishna Syarif in Nusa Dua, Badung, Bali, Tuesday (6/2/2018). The total number of work accidents in 2017 was 123 thousand cases with a claim value of more than Rp 971 billion. This figure increased from 2016 with a claim value of only Rp. 792 billion. Especially for Jakarta, there was an increase in the number of work accidents by 10 percent in 2017.

The government, in this case the Minister of Manpower of the Republic of Indonesia Mr. Hanif Dhakiri, said that the government will look for the causes of work accidents that have occurred several times recently. Is it related to a lack of occupational safety and health experts or caused by human error. Based on BPS statistics, there are around 8.3 million workers in the construction sector or around $6.7 \%$ of Indonesia's population, according to BPJS Ketenagakerjaan data, work accidents outside the workplace (on the road) are dominated by processing and construction activities. . Apart from the loss, both physically disabled / dead as well as financial losses which are quite large and significant for the government, in this case BPJS Ketenagakerjaan, the accusation of "human error factor - Human Error" being the cause of work accidents adds to the impression that Indonesian workers do not care. with their work safety?

This encourages us to investigate further what factors influence the safety behavior of workers in the construction activity sector so that later the results of this study will contribute to efforts to reduce the number of work accidents in the workplace, especially in the construction sector, the benefits of which are of course for workers, employers, society and of course the government. So that the purpose of the state being present and protecting the basic rights of the people at work can be realized. Research The construction activity sector in question is construction is the process of building a building or infrastructure. Construction 
differs from manufacturing in that manufacturing usually involves the mass production of similar goods without a designated buyer, whereas construction is usually carried out on site for known customers. Construction as an industry comprises $6 \%-9 \%$ of the gross domestic product of developed countries. Construction starts with planning, design, and financing; this continues until the project is built and ready to use.

Large-scale construction requires collaboration across disciplines. A project manager usually manages the budget on the job, and a construction manager, design engineer, construction engineer or architect supervises it. Those involved with design and implementation must consider zoning requirements, environmental impact of work, scheduling, budgeting, construction site safety, availability and transportation of building materials, logistics, inconvenience to the public caused by construction delays and bidding. Construction is a general term that means the art and science of forming objects, systems, or organizations. To build is a verb: the act of building, and noun construction: how a building is constructed, the nature of its structure. Broadly speaking, there are three construction sectors: buildings, infrastructure and industry. Building construction is usually further divided into residential and non-residential (commercial / institutional). Infrastructure is often called heavy or heavy civil engineering which includes major public works, dams, bridges, roads, railways, water or wastewater and utility distribution. Industrial construction includes refineries, process chemicals, power plants, factories and mills. There are also other ways to break down industries into sectors or markets. Batam as a free trade zone has its own features and appeal for construction activities. Construction activities such as building houses, hotels, apartments / flats, shipbuilding and ship repair fabrication, offshore installation fabrication, oil and gas industry fabrication in Batam will be respondents in this research.

\section{Literature Review \\ Management Commitment}

Commitment is a promise that is truly stated and really wants to be kept by using all available and available resources. Company commitment has an important role in safety performance that leads to safety behavior. However, small and medium companies lack financial resources and management commitment to improve their own safety performance compared to large companies (Lin and Mills, 2001). Managing commitment to safety has a meaning about the extent to which in general construction and personnel management places a high priority on safety, and communicates and acts on safety issues effectively (Neal and Griffin, 2006). Management commitment to safety has been identified as a core indicator of safety climate, which has been associated with increased safety behavior and decreased injury severity in the construction industry (Dedobbeleer and Béland, 1991; Mohamed, 2002; Gillen et al., 2002; Pousette et al., 2008). When top management is perceived as placing a high commitment to safety, job inspectors and workers tend to meet this expectation by increasing willingness to engage in daily safety practices (Guo et al., 2016).

\section{Training}

Safety training opens workers' understanding of the possibilities that may occur while they are doing work. Where by knowing the risks in doing work, it is expected to raise awareness of safety in doing work. The fundamental difference between workers who are safety conscious and those who are frequently injured is that workers who are safety conscious can recognize hazards and dangerous actions and understand the consequences (Vredenburgh, 2002; Pfeffer and Veiga, 1999) have shown that training is an important component in any organization because organization rely on frontline employee skills and initiative to identify and resolve problems, to initiate changes in work methods, and take responsibility for safety.

When attitudes toward increasing safety, safe behavior tends to follow (Ajzen, 1991). In order for employees to do their job properly and to be active participants in safety programs, they must receive occupational safety training. Such training is a process by which a lack of skills or knowledge that could impact safety is met by providing information and helping individuals to practice, in a supportive learning environment, the skills necessary to carry out activities safely. When employees are properly trained regarding safety precautions, safety rules and procedures, their safety performance improves (DeJoy et al., 2000; Harvey et al., 2001; Zohar, 2002; Roughton, 1993) explaining that safety training is recognized as something that is recognized. a way to make incidents more avoidable. To improve the quality of safety for all employees, the organization should establish a systematic and comprehensive safety training program for them. Companies should also institute a system of continuous re-education and retraining of employees in current crossing and safety operations. Because workers who have received safety training will have better safety behavior and work practices than those who have not received such training.

\section{Co-worker Influence}

Given the characteristics of construction work undertaken in small work groups, and where members engage in a lot of physical activity, imposes discretion in the interpretation of organizational safety policies and procedures, the role of colleagues in shaping a group-level safety climate is likely to be significant (Lingard et al., 2010a). 


\section{Leadership}

Construction activities are generally work that is not carried out routinely and therefore requires a work supervisor policy to interpret and take a stand on the interpretation of formal safety policies / procedures. In this context, the role of supervisors in shaping subordinate safety behavior tends to be much larger than in the context of work with routine production processes (Cooke et al., 2008). Considering the influence of supervisors on construction sites, a number of studies have been conducted to identify the role of supervisors in developing safety perceptions in the mindset of workers (Lingard et al, 2010b; Lingard et al, 2011b; Lingard et al., 2012; Zhou et al, 2015; Fang et al, 2015; Wu et al, 2015, Shen et al, 2015).

\section{Work Pressure}

Zohar suggests that safety climate perceptions should move beyond an isolated focus on safety, towards evaluations that combine relative priorities among various safety policies and procedures and their competing domains (eg construction work schedules) (Zohar, 2010). The negative effects of conflict between production schedules and safety have been examined by previous studies (Choudhry and Fang, 2008; Flin et al., 2000; Han et al., 2013; Mohamed, 2002; Mullen, 2004; Seo, 2005). Mullen (2004) suggests that construction workers behave unsafe not because they are not aware of the risks involved, but because of the job pressure exerted by supervisors and managers. Therefore, workers take shortcuts to satisfy their superiors and avoid negative consequences. Thus, production pressure tends to lead to unsafe behavior by reducing worker safety motivation. In addition, work pressure can make managers temporarily stop safety programs and thus some safety practices (eg, training, safety meetings) can be neglected to keep up with the schedule. Therefore, work pressure can have a negative impact on worker safety factors. And factors related to work speed and workload appear in a number of surveys and have been labeled work pressure. A related theme, which overlaps with this variable (and management and supervision factors) is the balance maintained between pressure for work schedules and safety, now widely recognized as a key component of safety culture (ACSNI, 1993).

\section{Safety Behavior}

Safety behavior - Safety Behavior according to Choudhry (2014) argues that behavior is whatever a person does or says. Psychologically, behavior is the action or reaction of people in response to external or internal stimuli (Choudhryet et al., 2009). Work behavior that is relevant to safety can be conceptualized in the same way as any other work behavior which is performance. From the point of view of accident investigation, unsafe construction worker behavior is often the main cause of accidents on construction sites (Reason et al., 1998). It was identified that $88 \%$ of accidents in construction projects involve unsafe behavior (Suraji et al, 2001).

Work behavior that is relevant to safety can be conceptualized in the same way as any other work behavior which is a performance performance (Grien and Andrew, 2000). Traditionally, safety performance is primarily measured by indicators such as accident rate, Total Recordable Injury Frequency Rate - TRIFR (total recorded injury frequency), and death rate to monitor safety performance (Guo et al., 2016). It is noteworthy that such measures have been criticized for being reactive in nature and providing no early warning of potential accidents. Previous research has also shown that safety behavior can predict accident and injury rates (Neal and Gri, 2006; Khosravi et al, 2015; Liu et al, 2015).

\section{Hypotheses Development \\ Management Commitment}

Management commitment to safety is considered as one of the most fundamental safety climate factors (Flin et al., 2000; Neal and Griffin, 2004). And where Neal and Griffin (2004) define safety commitment management as how important it is for management to prioritize safety as the first and communicate and act on safety issues effectively. The effect of safety commitment management on safety performance has been widely researched and its importance has been widely recognized (Al-Refaie, 2013; Fruhen et al., 2013; Hofmann and Morgeson, 1999; Hofmann and Stetzer, 1996; Michael et al., 2005) . The importance of management's commitment to safety in safety lies in the wide range of influences on safety management strategies, conflicts between construction and safety activities. When top management is perceived as placing a high commitment to safety, supervisors and workers may want to meet top management's expectations by increasing their willingness to engage in day-to-day safety practices.

The safety climate studies show that these perceptions are socially transmitted into collective norms and values in various hierarchical levels (Lingard et al., 2012). This proposition has been supported by empirical evidence in the construction industry (Lingard et al., 2012; McDonald et al., 2009; Molenaar et al., 2009). Organizational Citizenship Behavior, namely the behavior of employees that shows a positive influence on the organization because they have unselfish behavior, but they are highly social beings. Employees like this have very good performance which can improve the company by being the driving force in an organization, with this kind of behavior it will make it easier to communicate and interact with organizational colleagues, and minimize the obstacles to problems which can increase efficiency (Novliadi, 2016). Previous research 
linked Organizational Citizenship Behavior and Employee Performance was tested by researchers such as (Kambiz, 2013) (Uddin, 2018).

H1: Management safety commitment have a significant positive effect on safety behavior.

\section{Training}

According to job performance theory (Campbell et al., 1993), safety motivation predicts safety participation and safety compliance (Maier, 1955; Vroom, 1964), performance is determined by an interaction of motivation and knowledge. Safety Scientist (Neal et al., 2000; Vinodkumar and Bhasi, 2010) namely knowledge of safety when explaining safety behavior. For example, (Christian et al. (2009) explained that safety performance is closely related to safety knowledge and safety motivation. Similarly, (Brown et al. (2000) found that workers' attitudes about safety and safety effectiveness are significantly related to safety behavior. Neal et al, 2000) also found safety motivation and safety knowledge predict safety compliance and safety participation.

H2: Training have a significant positive effect on safety behavior.

\section{Co-worker Influence}

There is evidence that supervisors and coworkers have an important influence on safety climate and outcomes in a construction context. For example, (Choudhry and Fang, 2008) report that when co-workers and job supervisors are perceived as unsustainable for safety, construction workers are more likely to adopt unsafe work practices. Arguably, the part of the safety climate should be a stronger predictor of safety performance than the organization-level safety climate, especially in large organizations, as most workers have little contact with top management and are more likely to be affected by interactions with their immediate group of workers, including supervisors. and colleagues (Lingard et al., 2010a). In large and complex organizations, it is expected that employees develop shared perceptions of coworkers safety supervision and supervisory safety leadership (Lingard et al., 2009). According to job performance theory (Campbell et al., 1993), safety motivation predicts safety participation and safety compliance (Maier, 1955; Vroom, 1964), performance is determined by an interaction of motivation and knowledge. Safety Scientist (Neal et al., 2000; Vinodkumar and Bhasi, 2010) namely knowledge of safety when explaining safety behavior. For example, (Christian et al. (2009) explained that safety performance is closely related to safety knowledge and safety motivation. Similarly, (Brown et al. (2000) found that workers' attitudes about safety and safety effectiveness are significantly related to safety behavior. Neal et al, 2000) also found safety motivation and safety knowledge predict safety compliance and safety participation.

\section{H3: Co-worker influence have a significant positive effect on safety behavior.}

\section{Leadership}

Supervisors have the most frequent contact with workers between levels of the organizational hierarchy and are directly responsible for ensuring good safety performance in the workplace. The response or response of the first level supervisor on safety is the main determinant in the creation of subordinate beliefs about the importance of safety for the organization (Zohar and Luria, 2004). The implication of this is that the desired security values and behaviors must be supported across the hierarchies of different levels of the organization, and first-level supervisors play a key role in translating top management's safety commitments into safety values and practices in the work group. The importance of the relationship between supervisors and workers in the construction sector has been established and is recognized to be more significant than other work arrangements (Lingard et al., 2012; Fang et al., 2015).

\section{H4: Leadership have a significant positive effect on safety behavior.}

\section{Work Pressure}

In the global economy, increasing competitiveness, reducing costs and restructuring organizations. Work pressure is very likely to affect the safety climate in the workplace when time and resources become stretched. Performance is doing a task in line with the job description which can result in achievement in accordance with the perfection of what Rizwa et al., (2014) wants. Employee performance is the achievement or measure of success or failure in the job which is determined by various factors. In fact, individual employee performance has a significant influence, both from individual employees (internal factors), or organizational environmental conditions (external factors) which are also the actions of the company. The internal factors, for example, are motivation, expectations, goals, and others. And external factors, namely the scope of the inside and outside the company. Having a performance that can be proud of is one of the achievements that the entire company as a whole wants. If employees perform their duties properly, they can provide separate achievements for the company. vice versa, if the employee's performance is bad it will also have a negative effect on the company (Ahmad et al., 2014).

H5: Work pressure have a significant positive effect on safety behavior. 


\section{Research Methods}

The population in this study consists of Occupational Health and Safety Officer (AK3) at 85 construction companies in Batam with a total of 256 people. The samples in this study consist of 79 Occupational Health and Safety Officer (AK3) who worked at 85 construction companies in Batam. This study uses total sampling technique, using a questionnaire instrument. The method used is Slovin method and the data analysis used is SPPS.

This type of research is a case study research objective, which is to explore the factors as determinants that are seen as causing an outcome (Creswell, 2010). The data approach used in this research is field data (primary data) cross sectional quantitative type continuum. The quantitative research method asks several people (respondent) about beliefs, opinions, characteristics of an object and past or present behavior (Neuman W. Lawrence, 2003). Respondents will then be given several questions that will be selected in response to these questions.

\section{Result and Discusssion}

\section{Validity Test and Realibility Test}

Based on the results of the validity test, it shows the overall AVE results, there are 5 variables that fall into the valid criteria, because it has AVE values, namely management commitment (0.777), training (0.817), co-worker influence (0.756), leadership (0.888), and work pressure (0.724).

From the data processing reliability shows the calculation of composite reliability for the management commitment of 0.859 , training of 0.797 , co-worker influence of 0.847 , leadership of 0.946 , and work pressure of 0.759 . These results show that all variables have a composite reliability that is a level higher than 0.60 Hair et al. (2011).

\section{Hyphoteses Testing}

Results of hypothesis testing in Table 1 shows that $\mathrm{H} 1, \mathrm{H} 2, \mathrm{H} 3, \mathrm{H} 4$, and $\mathrm{H} 5$ are accepted with a probability value of 0.000 .

Table 1. Hypotheses Testing

\begin{tabular}{lcc}
\hline \multicolumn{1}{c}{ Variable } & P-Values & Conclusion \\
\hline Management Commitment $->$ Safety Behavior & 0,000 & H1 is accepted \\
\hline Training -> Safety Behavior & 0,000 & H2 is accepted \\
\hline Co-worker Influence -> Safety Behavior & 0,000 & H3 is accepted \\
\hline Leadership - S Safety Behavior & 0,000 & H4 is accepted \\
\hline Work Pressure -> Safety Behavior & 0,000 & H5 is accepted \\
\hline
\end{tabular}

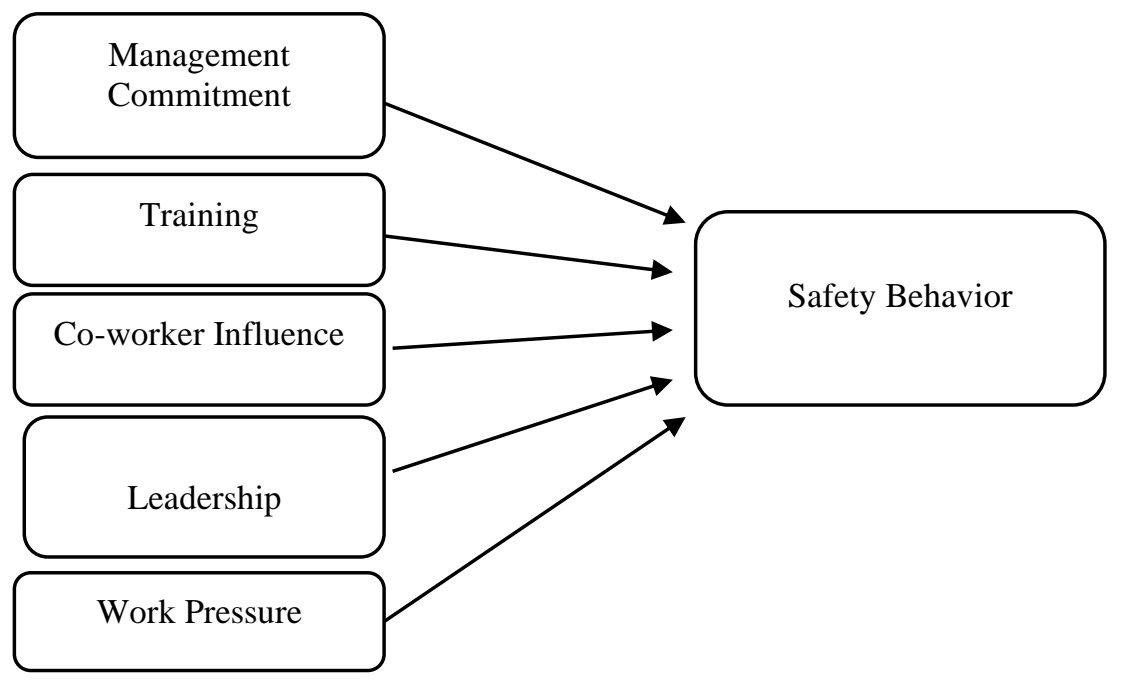

Figure 1. Research Model

According to the result of the $t$ test, it is known that the management commitment variable has a significant positive effect to safety behavior in this study as evidenced by a signifance value of 0.000 . The results of this study are in line with the research conducted by Goh et al. (2018). Management Commitment provides an influence on safety behavior - Safety Behavior. This is because the sources of production, both workers, equipment, work materials, work methods and the work environment are controlled and regulated by the management of the construction activity company. It is possible that in reducing the production costs of their labor, they select and recruit workers who do not pay attention to work requirements such as the 
obligation to have a competency certificate and other work requirements that are below the qualification standards, the factors that affect safety behavior-Safety Behavior.

Based on the results of the $t$ test, it is known that the training variable has a significant positive effect to safety behavior in this study as evidenced by a significance value of 0.000 . The results of this study are in line with the research conducted by Laurent et al. (2018). Based on the result of the $t$ test, it is known that the co-worker influence variable has a significant positive effect to safety behavior in this study as evidenced by a significance value of 0.000 . The results of this study are in line with the research conducted by Choudhry (2013) and Newaz et al. (2019). Co-worker influence and training - training provides additional leverage. This can be understood if workers work in carrying out their job activities and their work behavior is influenced by colleagues in making decisions. This is also influenced by the level of expertise or competence of the worker. This is interrelated considering that many construction workers at the operational level come from workers with low education levels or unskilled laborers who rely on labor and not expertise. Often found in construction activities, for example masons and Many of those who work do not understand the basic knowledge of cement mixing or the basis of welding through competency-based education or training, so that the quality of their work is often repeated in the workplace through informal input or training among their fellow co-workers who learn a lot self-taught and do not pay attention to safety factors at work.

Based on the results of the $t$ test, it is known that leadership variable has a significant positive effect to safety behavior in this study as evidenced by a significance value of 0.000 . The results of this study are not in line with the research conducted by Shen et al. (2017). Based on the results of the $t$ test, it is known that work pressure variable has a significant positive effect to safety behavior in this study as evidenced by a significance value of 0.000 . The results of this study are not in line with the research conducted by Wang et al. (2018) and Bronkhorst (2015). Leadership and Work Pressure provide significant weight in influencing work safety behavior - Safety Behavior in construction activities. Construction activities that provide many resource limitations including working time provide Work Pressure - Work Pressure that is sufficient to affect safety behavior - Safety Behavior where this condition will be realized if it has leadership support Leadership leaders who supervise workers in construction activities to prioritize safety in work or vice versa neglect their safety at work. The dynamics of construction activities in the midst of competition between construction activity contractors are broadly in the midst of business demands (Project Owner / Client) oriented to Quality, Cost and Delivery (QCD) amidst limited production sources for construction activities, bringing group 1: The Work Order Factor of construction activities is very dominant in influencing safety behavior factors - Safety Behavior.

\section{Conclusion}

The results of this study lead to the conclusion that the assumptions used as a references are indeed proven to contribute to work safety behavior in construction activities. Leadership and work pressure factors both together as the dominant factors affecting worker safety behavior in construction activities in Batam are followed by the influence of co-workers, training, and company management commitment in sequence as factors contributed. This needs to be a concern in construction activities in Batam. Limited resources in construction activities trigger whether work safety behavior is implemented or neglected. This of course affects the performance of construction activities which leads to a commitment to completion of construction work and the objectives of the company organization in general.

\section{References}

Al-Refaie, A. (2013). Factors affect companies' safety performance in Jordan using structural equation modeling. Safety Science. https://doi.org/10.1016/j.ssci.2013.02.010

Amponsah-Tawaih, K., \& Adu, M. A. (2016). Work Pressure and Safety Behaviors among Health Workers in Ghana: The Moderating Role of Management Commitment to Safety. Safety and Health at Work. https://doi.org/10.1016/j.shaw.2016.05.001

Barbaranelli, C., Petitta, L., \& Probst, T. M. (2015). Does safety climate predict safety performance in Italy and the USA? Cross-cultural validation of a theoretical model of safety climate. Accident Analysis and Prevention, 77, 35-44. https://doi.org/10.1016/j.aap.2015.01.012

Bronkhorst, B. (2015). Behaving safely under pressure: The effects of job demands, resources, and safety climate on employee physical and psychosocial safety behavior. Journal of Safety Research. https://doi.org/10.1016/j.jsr.2015.09.002

Choudhry, R. M. (2014). Behavior-based safety on construction sites: A case study. Accident Analysis and Prevention. https://doi.org/10.1016/j.aap.2014.03.007

Choudhry, R. M., \& Fang, D. (2008). Why operatives engage in unsafe work behavior: Investigating factors on construction sites. Safety Science. https://doi.org/10.1016/j.ssci.2007.06.027

Cooper, M. D., \& Phillips, R. A. (2004). Exploratory analysis of the safety climate and safety behavior relationship. Journal of Safety Research, 35(5), 497-512. https://doi.org/10.1016/j.jsr.2004.08.004

Cui, L., Fan, D., Fu, G., \& Zhu, C. J. (2013). An integrative model of organizational safety behavior. Journal of Safety Research. https://doi.org/10.1016/j.jsr.2013.01.001 
Demirkesen, S., \& Arditi, D. (2015). Construction safety personnel's perceptions of safety training practices. International Journal of Project Management, 33(5), 1160-1169. https://doi.org/10.1016/j.ijproman.2015.01.007

F.W, G. (2000). The nature of safety culture: a review of theory and research. Safety Science, 34(1-3), 215257. www.elsevier.com/locate/ssci

Fernández-Muñiz, B., Montes-Peón, J. M., \& Vázquez-Ordás, C. J. (2017). The role of safety leadership and working conditions in safety performance in process industries. Journal of Loss Prevention in the Process Industries, 50(November), 403-415. https://doi.org/10.1016/j.jlp.2017.11.001

Flin, R., Mearns, K., O’Connor, P., \& Bryden, R. (2000). Measuring safety climate: Identifying the common features. Safety Science, 34(1-3), 177-192. https://doi.org/10.1016/S0925-7535(00)00012-6

Fogarty, G. J., \& Shaw, A. (2010). Safety climate and the Theory of Planned Behavior: Towards the prediction of unsafe behavior. Accident Analysis and Prevention. https://doi.org/10.1016/j.aap.2009.08.008

Goh, Y. M., Ubeynarayana, C. U., Wong, K. L. X., \& Guo, B. H. W. (2018). Factors influencing unsafe behaviors: A supervised learning approach. Accident Analysis and Prevention, 118(September 2017), $77-$ 85. https://doi.org/10.1016/j.aap.2018.06.002

Griffin, M. A., \& Neal, A. (2000). Perceptions of safety at work: a framework for linking safety climate to safety performance, knowledge, and motivation. Journal of Occupational Health Psychology, 5(3), 347358. https://doi.org/10.1037/1076-8998.5.3.347

Guldenmund, F. W. (2000). The nature of safety culture: A review of theory and research. Safety Science, 34(1-3), 215-257. https://doi.org/10.1016/S0925-7535(00)00014-X

Guo, B. H. W., Goh, Y. M., \& Le Xin Wong, K. (2018). A system dynamics view of a behavior-based safety program in the construction industry. Safety Science, 104(September 2017), 202-215. https://doi.org/10.1016/j.ssci.2018.01.014

Guo, B. H. W., Yiu, T. W., \& González, V. A. (2016). Predicting safety behavior in the construction industry: Development and test of an integrative model. Safety Science, 84, 1-11. https://doi.org/10.1016/j.ssci.2015.11.020

Haslam, R. A., Hide, S. A., Gibb, A. G. F., Gyi, D. E., Pavitt, T., Atkinson, S., \& Duff, A. R. (2005). Contributing factors in construction accidents. Applied Ergonomics, 36(4 SPEC. ISS.), 401-415. https://doi.org/10.1016/j.apergo.2004.12.002

Hofmann, D. A., \& Stetzer, A. (1996). A cross-level investigation of factors influencing unsafe behaviors and accidents. Personnel Psychology, 49(2), 307-339. https://doi.org/10.1111/j.1744-6570.1996.tb01802.x

Jasiulewicz-Kaczmarek, M., Szwedzka, K., \& Szczuka, M. (2015). Behaviour Based Intervention for Occupational Safety - Case Study. Procedia Manufacturing, 3(Ahfe), 4876-4883. https://doi.org/10.1016/j.promfg.2015.07.615

Jiang, L., Yu, G., Li, Y., \& Li, F. (2010). Perceived colleagues' safety knowledge/behavior and safety performance: Safety climate as a moderator in a multilevel study. Accident Analysis and Prevention. https://doi.org/10.1016/j.aap.2009.08.017

Johnson, S. E. (2007). The predictive validity of safety climate. Journal of Safety Research. https://doi.org/10.1016/j.jsr.2007.07.001

Kouabenan, D. R., Ngueutsa, R., \& Mbaye, S. (2015). Safety climate, perceived risk, and involvement in safety management. Safety Science, 77, 72-79. https://doi.org/10.1016/j.ssci.2015.03.009

Laurent, J., Chmiel, N., \& Hansez, I. (2018). Jobs and safety: A social exchange perspective in explaining safety citizenship behaviors and safety violations. Safety Science, 110(October 2017), 291-299. https://doi.org/10.1016/j.ssci.2018.08.027

Mazlina Zaira, M., \& Hadikusumo, B. H. W. (2017). Structural equation model of integrated safety intervention practices affecting the safety behaviour of workers in the construction industry. Safety Science, 98, 124-135. https://doi.org/10.1016/j.ssci.2017.06.007

Mullen, J. (2004). Investigating factors that influence individual safety behavior at work. Journal of Safety Research. https://doi.org/10.1016/j.jsr.2004.03.011

Neal, A., \& Griffin, M. A. (2006). A study of the lagged relationships among safety climate, safety motivation, safety behavior, and accidents at the individual and group levels. Journal of Applied Psychology, 91(4), 946-953. https://doi.org/10.1037/0021-9010.91.4.946

Newaz, M. T., Davis, P., Jefferies, M., \& Pillay, M. (2019a). The psychological contract: A missing link between safety climate and safety behaviour on construction sites. Safety Science, 112(October 2018), 917. https://doi.org/10.1016/j.ssci.2018.10.002

Newaz, M. T., Davis, P., Jefferies, M., \& Pillay, M. (2019b). Using a psychological contract of safety to predict safety climate on construction sites. Journal of Safety Research, 68(xxxx), 9-19. https://doi.org/10.1016/j.jsr.2018.10.012

Petitta, L., Probst, T. M., Barbaranelli, C., \& Ghezzi, V. (2017). Disentangling the roles of safety climate and safety culture: Multi-level effects on the relationship between supervisor enforcement and safety compliance. Accident Analysis and Prevention, 99, 77-89. https://doi.org/10.1016/j.aap.2016.11.012 
Seo, H. C., Lee, Y. S., Kim, J. J., \& Jee, N. Y. (2015). Analyzing safety behaviors of temporary construction workers using structural equation modeling. Safety Science, 77, 160-168. https://doi.org/10.1016/j.ssci.2015.03.010

Shen, Y., Ju, C., Koh, T. Y., Rowlinson, S., \& Bridge, A. J. (2017). The impact of transformational leadership on safety climate and individual safety behavior on construction sites. International Journal of Environmental Research and Public Health, 14(1), 1-17. https://doi.org/10.3390/ijerph14010045

Vinodkumar, M. N., \& Bhasi, M. (2010). Safety management practices and safety behaviour: Assessing the mediating role of safety knowledge and motivation. Accident Analysis and Prevention, 42(6), 2082-2093. https://doi.org/10.1016/j.aap.2010.06.021

Wang, D., Wang, X., \& Xia, N. (2018). How safety-related stress affects workers' safety behavior: The moderating role of psychological capital. Safety Science, 103(November 2017), 247-259. https://doi.org/10.1016/j.ssci.2017.11.020

Xia, N., Griffin, M. A., Wang, X., Liu, X., \& Wang, D. (2018). Is there agreement between worker self and supervisor assessment of worker safety performance? An examination in the construction industry. Journal of Safety Research, 65, 29-37. https://doi.org/10.1016/j.jsr.2018.03.001

Zhang, S., Shi, X., \& Wu, C. (2017). Measuring the effects of external factor on leadership safety behavior: Case study of mine enterprises in China. Safety Science. https://doi.org/10.1016/j.ssci.2016.12.017

Zohar, D. (1980). Safety climate in industrial organizations: Theoretical and applied implications. Journal of Applied Psychology. https://doi.org/10.1037/0021-9010.65.1.96 